\title{
INSTITUTOS FEDERAIS DE EDUCAÇÃO: UM NOVO PARADIGMA EM EDUCAÇÃO PROFISSIONAL E TECNOLÓGICA ? ${ }^{1}$
}

\author{
INSTITUTOS FEDERALES DE EDUCACIÓN: ¿UN NUEVO PARADIGMA EN \\ EDUCACIÓN PROFESIONAL Y TECNOLÓGICA?
}

\author{
FEDERAL INSTITUTES OF EDUCATION: A NEW PARADIGM IN \\ PROFESSIONAL AND TECHNICAL EDUCATION?
}

RESUMO: O presente artigo analisa a proposta de educação profissional e tecnológica dos Institutos Federais de Educação em implantação no Brasil desde 2008. Fundados teoricamente na filosofia de Jürgem Habermas e na pedagogia de Paulo Freire, a partir da análise da legislação pertinente e de entrevistas focalizadas, buscamos responder se a referida proposta representa um novo paradigma em educação profissional e tecnológica. Identificamos o conceito de emancipação como central na discussão, pelo fato de tal proposta apresentar em seus discursos a pretensão de emancipar. Algumas características da proposta como a superação da dicotomia entre capacitação técnica e formação humana, a proposição de currículo integrado, a verticalização, a formação para a criticidade, apontam para a superação de um histórico tecnicista, o que configura um novo paradigma em educação profissional e tecnológica.

PALAVRAS-CHAVE: Institutos federais de eEducação. Educação profissional e tecnológica. Emancipação.

RESUMEN: El presente artículo analiza la propuesta de educación profesional y tecnológica de los Institutos Federales de Educación en implantación en Brasil desde el año 2008. Fundados teóricamente en la filosofía de Jürgem Habermas y en la pedagogía de Paulo Freire, a partir del análisis de la legislación pertinente y de encuestas focalizadas, buscamos responder si la referida propuesta representa un nuevo paradigma en educación profesional y tecnológica. Identificamos el concepto de emancipación como central en la discusión por el hecho de que tal propuesta presenta en sus discursos la pretensión de emancipar. Algunas características de la propuesta como la superación de la dicotomía entre capacitación técnica y formación humana, la proposición de currículo integrado, la verticalización, la formación para la criticidad, apuntan para la superación de un histórico tecnicista lo que configura un nuevo paradigma en educación profesional y tecnológica.

PALABRAS CLAVE: Institutos federales de educación. Educación profesional y tecnológica. Emancipación.

1 O presente artigo resultou de pesquisa realizada no Programa de Pós-graduação em Educação da Universidade Federal do Rio Grande do Sul, cuja tese de doutorado foi defendida em 2012.

2 Doutor em Educação pela UFRGS (2012). Instituto Federal do Rio Grande do Sul - Campus Canoas. Email: vicente.zatti@canoas.ifrs.edu.br 
ABSTRACT: The present article analyze the technological and professional education proposal of the Federal Institutes of Education on deployment in Brazil since 2008. Founded theoretically in Jurgen Habermas philosophy and Paulo Freire pedagogy, from the analysis of the pertinent legislation and the targeted interviews, we search answer if the proposal mentioned represents a new paradigm in professional and technological education. We identify the emancipation concept as the central of the discussion for the fact of some proposal report in your discussions a emancipation pretension. Some proposal characteristics as a dichotomy between technical capacitation and human formation, the proposition of the integrated curriculum, the uprighting, the training for a creativity, appointed to a overcoming of one technicist historical that configure a new paradigm in technological and professional education.

KEYWORDS: Federal institutes of education. Technological and professional education. Emancipation.

\section{Introdução}

O presente artigo é resultado de parte da pesquisa de doutorado realizada no Programa de Pós-graduação em Educação da Universidade Federal do Rio Grande do Sul, cuja tese foi defendida em 2012. Analisa o modelo de educação profissional e tecnológica em implantação no Brasil desde 2008 com a criação dos Institutos Federais de Educação. A metodologia da pesquisa foi estruturada a partir do tripé: hermenêutica fundada na teoria do filósofo Jürgen Habermas e do educador Paulo Freire consideradas de forma complementar, análise de documentos legais pertinentes, análise de entrevistas focalizadas (pesquisa empírica). Trata-se de um estudo qualitativo que visa problematizar as possibilidades emancipatórias do modelo de educação profissional e tecnológica em implantação nos Institutos Federais de Educação. Adotamos a "entrevista focalizada" (MINAYO, 2009, p. 64), como método empregado na parte empírica da pesquisa, pois, como o processo de implantação dos Institutos Federais de Educação ainda está ocorrendo, existem poucos dados e poucos resultados conclusivos, desse modo, é importante um método que possibilite a discussão entre os entrevistados para que possam ser levantadas questões, temas, problemas centrais desse processo. Foram constituídos dois grupos de discussão focalizada, cada um composto por três professores de um mesmo Campus. Os grupos foram constituídos nos Campus Canoas e Caxias do Sul do Instituto Federal do Rio Grande do Sul (IFRS) e as entrevistas ocorreram respectivamente em 12 de março de 2012 e 19 de março de 2012. A configuração dos grupos com professores do mesmo Campus teve como objetivo primar

\footnotetext{
${ }^{3}$ Também conhecida como "grupo focal" ou "grupo de discussão focalizada".
} 
pela discussão, que é facilitada pelo fato de esses professores conviverem no exercício profissional. Segundo Minayo (2009, p.64), a entrevista focalizada utiliza entrevistados escolhidos de modo intencional com o objetivo de esclarecer um determinado problema. Os entrevistados assinaram Termo de Consentimento Livre e Esclarecido, no qual consta o número de $\mathrm{CPF}$ e assinatura dos mesmos. Em cumprimento aos termos de sigilo estabelecidos no Termo de Consentimento Livre e Esclarecido, ao longo do artigo as falas dos entrevistados aparecem desidentificadas. Quando citamos a fala de um professor especificamente a referência é feita através dos termos desidentificados Prof. 1, Prof. 2, Prof. 3, Prof. 4, Prof. 5, Prof. 6. Para a condução da discussão na entrevista foi utilizado um Roteiro para Entrevista Focalizada semiestruturado.

As categorias discutidas na entrevista surgiram a partir da discussão teórica fundada na pedagogia dialógica freireana e na teoria da ação comunicativa habermaseana e também na legislação que cria e orienta a implantação dos Institutos Federais de Educação. Quanto à legislação, tomamos como referência principal a Lei 11.892, de 29 de dezembro de 2008 que cria os Institutos Federais de Educação e o documento elaborado pelo MEC em 2010 denominado Instituto Federal de Educação, Ciência e Tecnologia: Um modelo em educação profissional e tecnológica. Concepção e Diretrizes. A partir do tripé análise teórica, análise documental e entrevista focalizada, desenvolvemos abaixo algumas das categorias levantadas na pesquisa e que buscam discutir se a proposta educacional dos Institutos Federais de Educação representa ou não um novo paradigma na educação profissional e tecnológica brasileira. Tomamos como referência para tal discussão a concepção de educação emancipatória desenvolvida a partir da complementariedade do pensamento de Habermas e Freire.

\section{Superação da dicotomia entre formação humana e capacitação técnica}

Merece destaque como dado fundamental para a pesquisa, a partir da análise da legislação e das entrevistas, a prevalência de um discurso que caracteriza a educação profissional e tecnológica dos Institutos Federais de Educação como emancipatória. Isso aparece já na lei de criação dos Institutos Federais de Educação, a Lei 11.892/2008, no seu Artigo $7^{\circ}$, inciso V: "estimular e apoiar processos educativos que levem à geração de trabalho e renda e à emancipação do cidadão na perspectiva do desenvolvimento socioeconômico local e regional". A emancipação é citada, na lei acima, em relação com a cidadania e, esta, ao desenvolvimento socioeconômico local e regional. Portanto, 
emancipação está definida como relacionada à transformação da realidade na qual essas instituições inserem-se, o que está de acordo com a concepção de educação emancipatória de Paulo Freire. Mas isso não significa que a educação emancipatória se reduz à transformação da realidade material. Além de a legislação estabelecer a emancipação como tema da educação profissional e tecnológica, os entrevistados da pesquisa citaram como característica que diferencia a educação profissional e tecnológica dos Institutos Federais de Educação, em relação aos outros modelos de educação técnico-científica, o propósito de constituir uma educação emancipatória. Também para Juracy (2009, p. 40), "No espírito da lei, percebe-se como eixo de atuação dessas instituições um projeto de formação emancipatória." Desse modo, a grande inovação da proposta de educação profisssional e tecnológica dos Institutos Federais de Educação é buscar implantar uma educação emancipatória.

Nas entrevistas foi constatado que todos os membros dos grupos entrevistados caracterizaram a proposta educacional dos Institutos Federais de Educação como uma proposta que se estabelece com um discurso em prol da emancipação. Isso, para eles, representa um avanço em relação aos modelos anteriores, que de modo geral se restringiam à capacitação técnica. Mesmo que na prática a realização de tal perspectiva emancipatória apresente alguns problemas, é um avanço importante o fato de esta perspectiva estar estabelecida na legislação.

O grande consenso inicial ${ }^{4}$ obtido entre os grupos e participantes entrevistados foi que a proposta dos Institutos Federais de Educação é emancipatória na medida em que se propõe a superar a dualidade entre formação humana e capacitação técnica, de tal modo a não haver prevalência de um sobre o outro. Ou seja, o conceito mais inicial, que de imediato foi colocado por todos, é que a educação profissional e tecnológica emancipatória é aquela que remete à integração e não fica restrita aos componentes técnicos. Eliezer Pacheco, Secretário de Educação Profissional e Tecnológica do MEC de 2005 até 2012 e, portanto, um dos responsáveis pela implantação do projeto dos Institutos Federais de Educação, põe a emancipação como um dos objetivos basilares desse modelo educacional: "Assim, derrubar as barreiras entre ensino técnico e o científico, articulando trabalho, ciência e cultura na perspectiva da emancipação humana, é um dos objetivos basilares dos Institutos.” (PACHECO, 2010, p.14). A

${ }^{4}$ Refiro-me à grande consenso inicial, pois ao serem perguntados sobre o que é educação emancipatória todos fizeram referência imediata à educação que não se restringe à capacitação técnica e está voltada para a formação de modo mais amplo. 
educação que se estabelece na articulação entre trabalho, ciência e cultura, é uma educação que está voltada para a formação do humano além da técnica.

A primeira definição de educação profissional e tecnológica emancipatória dada na primeira entrevista pelo Prof. 1 foi "Emancipação é trabalhar além da técnica, não focar só na técnica, esse era o problema que tinha nos CEFETs" ${ }^{5 \%}$. Ao referir-se ao modelo de educação dos CEFETs há uma contestação à educação que se restringe à capacitação técnica. Na definição de educação profissional e tecnológica emancipatória dada pelo Prof. 6, a complementaridade entre a capacitação técnica e uma formação mais ampla ocupa papel central: "Entendo emancipação em dois sentidos complementares, que capacite tecnicamente para atuar no mercado de trabalho e que forme para atuar como cidadão que seja capaz de reflexão crítica. Representa a possibilidade do sujeito se formar trabalhador e cidadão crítico.” A formação humana e capacitação técnica são complementares e necessárias para o homem que trabalha para produzir e reproduzir seu modo de vida social. No que se refere a essa ligação de complementaridade, em A lógica das ciências sociais, afirma Habermas (2011, p. 37):

\begin{abstract}
A opinião de que as compulsões materiais técnicas teriam se autonomizado é ideológica. [...] A interpretação urgente que se estende até a inserção de meios técnicos no mundo da vida social precisa realizar as duas coisas ao mesmo tempo: ela precisa analisar as condições objetivas de uma situação, as técnicas disponíveis e factíveis, assim como as instituições existentes e os interesses efetivos, e, ao mesmo tempo, interpretá-los no âmbito de uma autocompreensão de grupos sociais de determinada tradição.
\end{abstract}

Desse modo, a educação profissional e tecnológica pode ser emancipatória na medida em que os elementos da formação humana e capacitação técnica coexistam. Ao não se restringir a elementos de capacitação técnica, essa proposta não está voltada, enquanto proposta, apenas ao desenvolvimento econômico, como afirma o entrevistado Prof. 5: "A proposta é ousada na medida em que não se restringe ao econômico. Alia duas coisas que poderiam parecer contraditórias, ser emancipado crítico e ser emancipado economicamente. " Isso representa uma inovação se considerarmos o histórico tecnicista do ensino técnico no Brasil. Nesse sentido converge a fala do entrevistado Prof. 3, “a educação técnico-científica emancipatória tem como ocorrer desde que não se privilegie nenhuma área. Historicamente ou a área técnica ou propedêutica foram privilegiadas", portanto, formação humana e capacitação técnica são complementares e para evitarmos distorções elas devem aparecer em educação de

${ }^{5}$ Centros Federais de Educação Tecnológica 
forma integrada. Essa concepção também está de acordo com o que verificamos a partir da teoria de Freire e Habermas, a racionalidade instrumental e a racionalidade comunicativa/dialógica não estão separadas, elas são emancipatórias na medida em que ocorrem articuladas, pois ambas têm o mesmo pano de fundo como origem, o mundo da vida.

\section{Institutos federais de educação como herança e superação dos CEFETS}

Já na primeira fala da primeira entrevista acima citada surgiu a comparação entre os Institutos Federais de Educação e os CEFETs. Na verdade, a implantação dos Institutos Federais de Educação ocorreu a partir do potencial instalado dos CEFETs, das escolas técnicas e agrotécnicas federais e escolas vinculadas às universidades federais. Quando os entrevistados se referem aos CEFETs estão se referindo principalmente ao modelo de educação profissional e tecnológica anterior aos Institutos Federais de Educação e não estritamente aos CEFETs ${ }^{6}$. A relação entre esses modelos institucionais apareceu especialmente em um dos grupos onde dois professores possuíam experiência como professores e um deles como aluno em CEFET. No outro grupo as comparações estabelecidas foram principalmente em relação ao Sistema $\mathrm{S}$, em função das experiências dos professores entrevistados.

$\mathrm{Na}$ fala do entrevistado Prof. 1 nos CEFETs, a formação para além da técnica não ocorria. De modo geral os entrevistados concordaram com essa ideia, mas houve alguns elementos dissonantes. Como não foi um tema consensual, passamos à explicitação das falas. O Prof. 3 teve experiência em CEFET no qual no turno da manhã tinha o ensino médio como em qualquer escola e a tarde o curso técnico e não necessariamente os alunos das duas turmas eram todos os mesmos, pois as matrículas eram separadas. Ou seja, o currículo não era integrado, o que dava ao ensino técnico um caráter tecnicista, enquanto o ensino médio adquiria características de preparação para o vestibular. Em função disso, segundo ele, nem todos os cursos do "CEFET eram necessariamente tecnicistas", mas a não integração estabelecia um dualismo entre os

\footnotetext{
${ }^{6}$ Esse esclarecimento é importante para que não haja uma compreensão equivocada da questão. Quando se referiam aos CEFETs os entrevistados falavam em tempo passado pois estavam se referindo ao modelo de educação profissional e tecnológica que havia na Rede Federal antes da implantação dos Institutos Federais de Educação. Há ainda hoje o CEFET-RJ e o CEFET-MG que não aderiram a mudança para Instituto Federal de Educação, mas a Lei 11.892/2008 no Artigo 18 os insere no novo reordenamento da educação profissional e tecnológica e os define como "instituições de ensino superior pluricurriculares, especializadas na oferta de educação tecnológica nos diferentes níveis e modalidades de ensino".
} 
cursos técnicos de caráter de preparação para o trabalho e cursos de ensino médio de preparação para a continuidade dos estudos. Comenta ainda que sua "primeira experiência de integração foi no curso do PROEJA, e a principal dificuldade foi os professores da área técnica se adaptarem com a ideia de integração”. Isso se deve ao fato evidente de esses professores terem atuado até então com cursos estritamente técnicos.

O entrevistado Prof. 5 concordou com a ideia de que os Institutos Federais de Educação possuem a formação emancipatória como central em sua proposta e que os CEFETs estavam voltados principalmente para a capacitação técnica, deixando demais aspectos a um plano secundário. No entanto, afirma "Não acredito que os CEFETs tenham formado somente a partir de uma visão tecnicista, senão não teriam verticalizado". Refere-se à verticalização, ou seja, oferecimento de diferentes níveis de ensino, como um indício de que nos CEFETs havia elementos que não estavam restritos à capacitação técnica. Nesse sentido, havia nessas instituições o embrião que tornou os Institutos Federais de Educação instituições de ensino superior. Para o Prof. 2, "a redução ao técnico ocorria em termos de grade curricular, em função da ênfase nas disciplinas técnicas e redução das disciplinas propedêuticas, mas o ambiente levava o aluno a assumir responsabilidades e possibilitava a emancipação". Para justificar sua argumentação, o entrevistado, que é professor em uma área das ciências humanas, disse que se interessou por essa área enquanto fazia curso técnico em CEFET, mesmo sem ter a disciplina na grade curricular. Isso chama a atenção para a importância de espaços educacionais de interação que não se restringem à sala de aula, o que debatemos no próximo item.

\section{Ambiente escolar/acadêmico como espaço interativo}

De acordo com a concepção de emancipação que estamos desenvolvendo a partir do pensamento de Habermas e Freire, a educação é um processo de interação e o processo de ensino/aprendizagem se estabelece fundado nisso. Freire (1983) demonstra que a humanização depende da interação, na medida em que não nos constituímos no "monólogo" e sim de forma intersubjetiva. "Por isto, o diálogo é uma exigência existencial" (FREIRE, 1983, p. 93). Assim, apreender é um ato interativo com os outros e com o mundo. Para Habermas (2002c) a superação da filosofia da consciência põe a interação como conceito de grandeza central: 
As relações recíprocas e interpessoais, determinadas pelos papéis do falante, tornam possível uma autorelação, que não precisa mais pressupor a reflexão solitária do sujeito agente ou cognoscente sobre si mesmo enquanto consciência prévia. A autoreferência surge de um contexto interativo. (HABERMAS, 2002c, p. 33).

A questão da interação e do potencial educativo das interações que se estabelecem no ambiente acadêmico/escolar apareceu na fala dos entrevistados. Ao debater a mudança ocorrida na rede federal de educação profissional e tecnológica que marcou a passagem dos CEFETs para os Institutos Federais de Educação, abordada no item anterior, o entrevistado Prof. 2, discordando da ideia que de modo geral foi aceita pelos demais, defendeu que mesmo os CEFETs, onde o discurso pedagógico de uma educação emancipatória não aparecia, conseguiam desenvolver uma educação emancipatória pois possuíam espaços de interação que compensavam o currículo restrito ${ }^{7}$. Segundo ele "a educação emancipatória ou não, não é apenas uma questão de grade curricular, o ambiente escolar, o contexto, também é significativo". Desse modo, o contexto, o ambiente e espaços escolares, possibilitaram a interação e aprendizagens que não estavam contempladas no currículo. Tal tese de que os espaços de interação possuem um papel importante na constituição de uma educação emancipatória, também foi defendida pelo entrevistado Prof. 6, pertencente ao outro grupo de discussão. A diferença é que ele fez isso afirmando espaços interativos possibilitados pelo modelo educacional dos Institutos Federais de Educação. Para ele as oportunidades que os Campus dos Institutos Federais de Educação oferecem de participação em atividades culturais, de pesquisa, de extensão, participação em Grêmio Estudantil e Diretório Acadêmico, participação em comissões e conselhos, possuem um papel importante para a formação do educando e desse modo, papel fundamental quando a questão é possibilitar uma educação emancipatória. Tais possibilidades são estabelecidas legalmente na Lei 11.892/2008 que cria os Institutos Federais de Educação com finalidades voltadas para ensino, pesquisa e extensão e estabelece uma estrutura organizacional com espaços de atuação para docentes, servidores técnicoadministrativos e discentes.

A questão da importância do ambiente escolar/acadêmico como espaço interativo emancipatório apareceu nos dois grupos a partir de exemplos diferentes e,

${ }^{7}$ Essa visão discordante do entrevistado que não identifica simplesmente a educação dos CEFETs como puramente técnica, corrobora a ideia consensual entre os entrevistados de que a educação emancipatória não se restringe à capacitação técnica, envolve formação humana e encontra sua base de legitimidade na interação social. 
merece destaque, de forma espontânea a partir da fala dos entrevistados. Embora a sala de aula também seja espaço interativo, é fundamental que a articulação ciência, trabalho e cultura apenas inicie em sala de aula e se estenda a outros espaços da instituição. Educar está relacionado ao mundo da vida e espaços de participação política, participação em projetos de extensão e pesquisa, são formas importantes de os alunos dos Institutos Federais de Educação estabelecerem interações qualificadas no espaço escolar/acadêmico e, desse modo, construírem aprendizagens que dificilmente seriam possíveis apenas através dos conteúdos e disciplinas da grade curricular. A tarefa da humanização é essencialmente intersubjetiva, restringir a formação à capacitação técnica negando a importância desses espaços interativos representa negar a humanização.

\section{O currículo integrado no ensino médio}

A importância da interação na constituição de aprendizagens nos indica que a educação profissional e tecnológica não pode estar desligada de uma formação mais ampla. Nesse sentido as Concepções e Diretrizes do modelo de educação implantado nos Institutos Federais de Educação, rompem com um modo fragmentário de lidar com o conhecimento e estabelecem a integração como conceito central para a educação emancipatória.

O fazer pedagógico desses institutos, ao trabalhar na superação da separação ciência/tecnologia e teoria/prática, na pesquisa como princípio educativo e científico, nas ações de extensão como forma de diálogo permanente com a sociedade, revela sua decisão de romper com um formato consagrado, por séculos, de lidar com o conhecimento de forma fragmentada. (MEC, 2010, p. 31).

A superação da fragmentação do conhecimento através da integração entre as disciplinas propedêuticas e técnicas tem como princípio a complementaridade e o rompimento da dualidade entre capacitação técnica e formação humana. As especificidades técnicas devem ser ensinadas levando em conta a totalidade da vida. Considerando a história da educação profissional e tecnológica no Brasil, é o Decreto $\mathrm{N}^{\mathrm{o}} 5.154$ de 23 de julho de 2004 que traz a possibilidade de integração entre educação profissional e o nível médio, o que não era contemplado na Resolução CNE/CEB No 04/99 e proibido na Resolução CNE/CEB Nº 03/98. O Decreto n ${ }^{\circ}$ 5.154/2004 abre caminho para a integração no ensino médio, pois estabeleceu que a educação 
profissional técnica de nível médio se daria através de três formas: integrada, concomitante e subsequente. A integrada ocorreria através de matrícula única, integrando os saberes técnicos e propedêuticos, de tal modo a conduzir o aluno à habilitação profissional técnica de nível médio. A concomitante ocorreria através de matrícula distinta, uma de ensino médio e outra de educação profissional técnica, podendo elas ser feitas na mesma ou em outra instituição. A subsequente é destinada a quem já concluiu o ensino médio. O grande mérito de tal legislação foi ter criado a possibilidade de integração no ensino médio.

Nos Institutos Federais de Educação, conforme Artigo $8^{\circ}$ da Lei 11.892/2008, $50 \%$ das vagas devem ser destinadas aos cursos de ensino médio, prioritariamente na forma de cursos integrados, e para educação de jovens e adultos. "Este novo arranjo educacional abrirá novas perspectivas para o ensino médio, por meio de uma combinação do ensino de ciências naturais, humanidades e educação profissional e tecnológica." (MEC, 2010, p. 3). A integração entre trabalho-ciência-tecnologia-cultura é necessária para a formação de trabalhadores capazes de ação e reflexão, capazes de superar as situações de minoridade que lhes são impostas. "O currículo integrado do ensino médio técnico visa à formação dos trabalhadores como dirigentes, tendo como horizonte a superação da dominação dos trabalhadores e perspectivas de emancipação." (RAMOS, 2010, p. 52). Desse modo, a integração curricular nos cursos de ensino médio representa um dos principais avanços na configuração de uma educação emancipatória nos Institutos Federais de Educação.

Segundo os entrevistados, em especial o segundo grupo enfatizou tal aspecto, há hoje uma tendência entre os pesquisadores da área de educação profissional e tecnológica, que se estabeleceu no plano do discurso teórico, na defesa dessa integração na educação profissional e tecnológica de Ensino Médio e da associação dessa integração com a perspectiva emancipatória. Essa integração representa a superação da dualidade entre a formação para o trabalho produtivo e a formação do cidadão. Segundo o entrevistado Prof. 3, "O técnico e formação humana tem que andar juntos, senão, não teremos nem bom cidadão nem bom técnico." A integração curricular abre possibilidades para que a formação do profissional qualificado tecnicamente esteja integrada à formação para a cidadania, com o que concorda Marise Ramos:

Nesse contexto, afirmamos que um projeto de ensino médio integrado ao ensino técnico tendo como eixos o trabalho, a ciência e a cultura, deve buscar superar o histórico conflito existente em torno do papel da 
escola, de formar para a cidadania ou para o trabalho produtivo e, assim, o dilema de um currículo voltado para as humanidades ou para a ciência e tecnologia, bem como a dicotomia entre conteúdos e competências. (RAMOS, 2010, p. 52).

De acordo com as Concepções e Diretrizes dos Institutos Federais de Educação (MEC, 2010, p. 27), a proposta de integração do ensino médio à formação técnica, além de estabelecer o diálogo entre os conhecimentos científicos, tecnológicos, sociais e humanísticos e conhecimentos e habilidades relacionadas ao trabalho e de superar o conceito da escola dual e fragmentada, pode representar a queda da hierarquização de saberes e colaborar para a educação brasileira como um todo, no desafio de construir uma nova identidade para essa última etapa da educação básica.

Os entrevistados ao longo de suas falas sempre mantiveram como pano de fundo a ideia de que o caminho para uma educação emancipatória passa pelo currículo integrado, de tal modo que para o entrevistado Prof. 1 "os cursos subsequentes não são adequados" aos Institutos Federais de Educação e ainda, os Prof. 1 e Prof. 3 manifestaram que os cursos integrados devem ser prioridade nos Institutos Federais de Educação. Houve consenso entre os grupos quanto à prioridade dos cursos integrados, mas não quanto à adequação ou não do oferecimento de ensino técnico subsequente, isso em função de que esses cursos subsequentes atendem pessoas que já concluíram o ensino médio e precisam de qualificação profissional, então, se de um lado o currículo se reduz a elementos técnicos, por outro abre uma possibilidade de qualificação para um público específico que em geral está em situação de exclusão. Quanto aos cursos técnicos concomitantes houve consenso que são inadequados se pretendermos educar na perspectiva emancipatória, isso porque tratam os saberes de forma fragmentada, perpetuando uma tradição que dicotomiza a capacitação técnica e formação humana.

\section{Superação da fragmentação: uma nova mentalidade de formação não dicotomizada}

Segundo os professores entrevistados, a visão fragmentada de educação profissional e tecnológica está perdendo espaço, há uma mudança de mentalidade, que tem origem no discurso teórico dos pesquisadores em educação profissional e tecnológica, atravessa a legislação recente e se estabelece como o pensamento corrente entre os professores que atuam nessa modalidade de educação: na educação profissional e tecnológica a formação técnica qualificada e a formação do cidadão aparecem como 
elementos não antagônicos. Sobre esse aspecto, a fala do Prof. 6 é ilustrativa: "Coisas que em determinados momentos históricos eram compreendidas como antagônicas, passam a ser compreendidas de outra forma. Exemplo disso é o conceito de desenvolvimento sustentável. Também é o caso da educação profissional e tecnológica, que não compreende a capacitação técnica de forma antagônica à formação humana". Ou seja, o entrevistado, com a concordância do grupo, afirma que o projeto dos Institutos Federais de Educação representa uma nova mentalidade que está se estabelecendo em educação profissional e tecnológica, a superação da fragmentação e dicotomia em favor da integração entre capacitação técnica e formação humana. $\mathrm{O}$ entrevistado Prof. 4, referindo-se à educação dos Institutos Federais de Educação, afirma que "a ideia é romper a dualidade que havia entre técnica e formação do sujeito, do cidadão, o que é uma tendência recente de, pelo menos no plano do discurso, superar esse dualismo".

A superação dessa fragmentação aponta para uma formação ampla, não restrita aos aspectos técnicos, tendo em vista que sempre estamos educando um ser humano que vive em sociedade, desse modo:

Não importa em que sociedade estejamos, em que mundo nos encontremos, não é possível formar engenheiros, pedreiros, físicos ou enfermeiras, dentistas ou torneiros, educadores ou mecânicos, agricultores ou filósofos, pecuaristas ou biólogos sem uma compreensão de nós mesmos enquanto seres históricos, políticos, sociais e culturais; sem uma compreensão de como a sociedade funciona.(FREIRE, 1999, p. 134).

Portanto, há elementos ligados à formação humana, à formação do cidadão que são necessários independente da área técnica na qual o sujeito vai atuar. Daí a necessidade de a educação não se reduzir à capacitação técnica. Segundo o entrevistado Prof. 4, "um dos nossos grandes objetivos (Institutos Federais de Educação) é de no dia a dia colocar em prática justamente uma educação que compreende a capacitação técnica e formação humana como elementos complementares". Segundo os entrevistados, os Institutos Federais de Educação estão conseguindo proporcionar, além da técnica, uma formação intelectual sólida, o que se dá pelo oferecimento de disciplinas das áreas de humanidades e a participação dos alunos em projetos e atividades dentro da instituição. Esses espaços implicam em oportunidades de convivência, interação, discussão que envolve alunos, professores e técnico- 
administrativos. Portanto, há a perspectiva da superação da fragmentação que cria um dualismo entre capacitação técnica e formação humana.

\section{Verticalização como forma de integração}

Se a integração do curso técnico com o ensino médio constitui um importante avanço para a superação da dualidade capacitação técnica versus formação humana, cabe perguntar: como a superação dessa dicotomização pode ocorrer também nos cursos superiores em tecnologia, técnicos subsequente, engenharias, bacharelados? Segundo os entrevistados, em especial um dos grupos no qual tal aspecto apareceu com maior força, a dicotomia entre formação humana e técnica pode ser superada nos demais níveis que não o ensino médio, através da verticalização. A Lei 11.892/2008 no seu Artigo 6º inciso III, ao referir-se às finalidades dos Institutos Federais de Educação: "promover a integração e a verticalização da educação básica à educação profissional e educação superior, otimizando a infraestrutura física, os quadros de pessoal e os recursos de gestão". Ou seja, integração e verticalização aparecem como elementos relacionados e que devem estar presentes em todos os níveis de ensino. Segundo o entrevistado Prof. 4 a verticalização está associada à integração, “pois a verticalização é uma forma de integrar diferentes níveis de ensino num mesmo ambiente educativo para potencializar o processo como um todo". A interação entre alunos de diferentes níveis de ensino de um mesmo eixo tecnológico, bem como interação também nas atividades de pesquisa e extensão, possibilita um espaço formativo emancipatório. Ao referir-se à educação emancipatória situada no modelo de educação que está sendo implantado nos Institutos Federais de Educação, o entrevistado Prof. 4 afirma: "uma marca é a verticalização, cursos do ensino médio ao doutorado, o que cria uma diversidade que é essencial, é saudável”. Essas afirmações dos entrevistados estão de acordo com o que afirma Pacheco:

Essa organização pedagógica verticalizada, da educação básica a superior, é um dos fundamentos dos Institutos Federais. Ela permite que os docentes atuem em diferentes níveis de ensino e que os discentes compartilhem os espaços de aprendizagem, incluindo os laboratórios, possibilitando o delineamento de trajetórias de formação que podem ir do curso técnico ao doutorado. (PACHECO, 2010, p. 13). 
Para potencializar essa integração possibilitada pela verticalização, os entrevistados consideraram imprescindível a organização dos cursos em torno de eixos tecnológicos específicos. Para o entrevistado Prof. 5: "não poderemos abranger muitas áreas, é preciso se restringir a certos eixos tecnológicos". Se não restringirmos os eixos tecnológicos, haverá dispersão e a interação entre profissionais da mesma área de diferentes níveis de ensino, bem como a possibilidade de os alunos percorrerem um itinerário formativo, serão anuladas. Portanto, oferecer cursos em diferentes níveis e modalidades dentro de um mesmo eixo tecnológico é fundamental tanto para que se possa atender diferentes grupos de estudantes e trabalhadores quanto para possibilitar que quem ingresse em um Instituto Federal de Educação tenha possibilidade de continuidade dos estudos na instituição. Desse modo a verticalização é uma questão de compromisso com todos.

Os Institutos Federais validam a verticalização do ensino na medida em que balizam suas políticas de atuação pela oferta de diferentes níveis e modalidades da educação profissional e tecnológica, tomando para si a responsabilidade de possibilidades diversas de escolarização como forma de efetivar o seu compromisso com todos. (MEC, 2010, p. 26).

Mas mesmo que a verticalização possa contribuir para a integração em todos os níveis de ensino, não há instrumentos legais que garantam que os cursos que não são de ensino médio não fiquem restritos a um currículo puramente técnico. Os professores entrevistados citaram exemplos de seus Campi quando na criação dos cursos superiores em tecnologia, apenas foram incluídas no currículo disciplinas da área de humanidades em função da atuação militante dos professores dessas áreas. Isso porque não há mecanismos legais que façam tais indicativos, e a inclusão das humanidades ou outros saberes que contribuiriam para a não redução à capacitação técnica, se torna uma questão de espaço a ser conquistado através do convencimento dos envolvidos nas elaborações dos PPCs dos cursos.

Outra dificuldade que surgiu a partir das falas dos entrevistados é que os Campi não estão tendo condições de implantar plenamente a verticalização. Como afirma o entrevistado Prof. 1, "a verticalização funciona em parte, não temos ainda pósgraduação". Como a verticalização é uma importante questão para a educação emancipatória, esse é um tema que deve receber maior atenção dos responsáveis pela implantação do projeto dos Institutos Federais de Educação. 


\section{Educação crítica}

As entrevistas realizadas e os documentos pesquisados apontam que a educação profissional e tecnológica emancipatória tem como característica central a integração dos conhecimentos técnico-científicos com a cultura, a política, a ética, enfim, a totalidade da vida. Ao referirem-se à educação integrada, um dos elementos mais destacados pelos entrevistados é que ela não se restringe aos conhecimentos técnicos e educa para a crítica. O termo educação crítica foi bastante citado, especialmente no segundo grupo entrevistado. Ao serem perguntados sobre o que é crítica, a resposta do Prof. 4 foi "crítica é a capacidade de assumir uma posição consciente em diferentes contextos, se posicionar de forma consciente frente aos contextos", o Prof. 6 "crítico é aquele que é capaz de olhar de novo para sua prática e melhorar, propor algo diferente". Ainda, o entrevistado Prof. 4 citou que no bojo da proposta dos Institutos Federais de Educação há uma herança freireana, no que se refere à ideia de educação crítica e à proposta comprometida socialmente. Na obra Pedagogia da autonomia, Freire dedica um subcapítulo ao tema "Ensinar exige criticidade", quando relaciona a criticidade com a superação da ingenuidade: "Precisamente porque a promoção da ingenuidade para a criticidade não se dá automaticamente, uma das tarefas precípuas da prática educativoprogressista é exatamente o desenvolvimento da curiosidade crítica, insatisfeita, indócil.” (FREIRE, 2007, p. 32).

Também em diferentes momentos das entrevistas quando se falava em educação integrada, apareceu a ideia de pensamento crítico, como na frase do Prof. 6: "A integração envolve a capacitação para o mercado de trabalho e formação para a cidadania, o que inclui o desenvolvimento de pensamento crítico. " A ideia de educação crítica aparece relacionada à ideia de cidadania, de posição consciente diante dos contextos da realidade, ou seja, remete à uma postura de interação frente à realidade com vistas à emancipação, o que também é indicado nas Concepções e Diretrizes da Educação profissional e tecnológica dos Institutos Federais de Educação:

A educação para o trabalho nessa perspectiva entende-se como potencializadora do ser humano, enquanto integralidade, no desenvolvimento de sua capacidade de gerar conhecimentos a partir de uma prática interativa com a realidade, na perspectiva da emancipação. (MEC, 2010, p. 33-34).

Essa capacidade de gerar conhecimentos a partir de uma prática interativa com a realidade não demanda apenas capacitação técnica, mas uma compreensão crítica da 
realidade que insere o trabalhador como agente político enquanto produz seus meios de vida. Tal perspectiva também é indicada nas diretrizes do MEC: "[...] essa formação do trabalhador seja capaz de tornar esse cidadão um agente político, para compreender a realidade e ultrapassar os obstáculos que ela apresenta. " (MEC, 2010, p. 33). Tal formação não estará qualificando apenas para atender as necessidades do mercado de trabalho, mas sim um cidadão para o mundo do trabalho. "Nosso objetivo central não é formar um profissional para o mercado, mas sim um cidadão para o mundo do trabalho, o qual poderia ser tanto técnico, como um filósofo, um escritor ou tudo isto". (PACHECO, 2010, p. 10-11). A formação desse cidadão para o mundo do trabalho supõe uma educação que não se restringe a elementos técnicos, mas aborda o político, o ético, o estético, enfim, busca desenvolvê-lo enquanto ser humano em suas dimensões múltiplas. A educação que possui o foco no mercado de trabalho é pouco eficiente até mesmo para atender os interesses do sistema, considerando que o mercado é volátil e está constantemente se redefinindo. Por isso na perspectiva emancipatória se compreende como fundamental a formação para o pensar crítico, para a reflexão, para uma postura intelectual frente ao conhecimento técnico-científico. Isso dá condições de o trabalhador não ficar submetido aos discursos ideológicos que se impõe no mercado e se adaptar de uma forma crítica às transformações que ocorrem no mundo do trabalho.

\section{Educação profissional e tecnológica e mundo da vida ${ }^{8}$}

Reforçamos que educação profissional e tecnológica, quando restrita aos seus aspectos técnicos, está incorrendo nos mesmos erros do positivismo ao desconsiderar que ciência e a técnica mantém uma inevitável referência ao mundo da vida. São sobre as experiências pré-científicas do mundo da vida que originariamente constituem-se as próprias ciências. Por maior objetividade que apresentem e por mais autônomas que sejam, é no mundo da vida que ciência e técnica encontram seu fórum de validade.

Porque nosso contato com o mundo é mediado linguisticamente, o mundo se exime igualmente tanto do acesso direto do sentido como de uma constituição direta, através das formas de entendimento. A objetividade do mundo, que supomos ao falar e agir, está de tal modo entrelaçada com a intersubjetividade do entendimento sobre algo no

${ }^{8}$ Os Institutos Federais de Educação fazem parte de uma estratégia sistêmica, são instituições criadas pelo subsistema político e estão permeadas por interesses que remetem ao subsistema econômico. Mas se ficarem restritos aos seus aspectos sistêmicos, inevitavelmente teremos uma educação tecnicista, daí a importância de em educação profissional e tecnológica considerar-se o humano a partir da complexidade do mundo da vida. 
mundo, que não damos um passo atrás desta correlação, da qual não nos podemos desviar, do horizonte revelado linguisticamente partilhado. (HABERMAS, 2002b, p. 56).

Por isso, segundo Habermas (1989, p. 75-76), o uso comunicativo da linguagem pressupõe o uso cognitivo mediante o qual dispomos de conteúdos proposicionais: e, o inverso, o uso cognitivo da linguagem, pressupõe o comunicativo, porque as orações assertórias só podem empregar-se em atos de fala constatativos. "Uma situação de entendimento possível exige que ao menos os falantes/ouvintes estabeleçam uma comunicação simultaneamente em ambos planos: no plano da intersubjetividade, em que os sujeitos falam entre si, e no plano dos objetos (ou estados de coisas) sobre o que se entendem". (HABERMAS, 1989, p. 83, tradução nossa). O mundo da vida é o "pano de fundo" apenas intuitivamente presente e absolutamente certo, do qual se desprendem as esferas daquilo sobre o qual se pode alcançar em cada caso um acordo falível. (cf. HABERMAS, 2002a, p.169). É algo que todos nós temos sempre presente, de modo intuitivo e não problemático, como sendo uma totalidade pré-teórica. (cf. HABERMAS, 2002c, p. 48). "O mundo da vida constitui, pois, o contexto da situação de ação, ao mesmo tempo, ele fornece os recursos para os processos de interpretação com os quais os participantes da comunicação procuram suprir a carência de entendimento mútuo que surgiu em cada situação de ação. " (HABERMAS, 2003, p. 167). Segundo Stein (2004, p. 46), o conceito de mundo da vida se liga a uma racionalidade que é a priori, enquanto ele é o limite para trás do qual não se pode recuar, é o já sempre dado. É esse pano de fundo intersubjetivamente partilhado que possibilita o entendimento entre os sujeitos. “Os processos de entendimento mútuo do mundo da vida carecem por isso de uma tradição cultural em toda sua latitude e não apenas das bênçãos da ciência e da técnica." (HABERMAS, 2003, p. 33). Ou seja, o progresso técnico e científico não tem uma legitimidade própria, eles estão interligados e interdependentes com esferas como ética, estética, política. Segundo Freire (1982, p.97) o conhecimento é o processo que implica ação e reflexão do homem sobre o mundo, de modo que a ciência está sempre relacionada com outras esferas da vida. A preocupação com a verdade e com a rigorosidade científica, não significa que a ciência é neutra. Por isso a educação profissional e tecnológica precisa manter seu horizonte formativo amplo, abordando a vida humana em sua amplitude. Tal abertura ao mundo da vida, para que se evite distorções positivistas, deve ocorrer não apenas nos cursos de ensino médio integrado, mas em todos os níveis de educação profissional e tecnológica. 
Como a técnica e a ciência mantém ligação com outras esferas do mundo da vida, e encontram seu fórum de validade no mundo da vida, a alegação de neutralidade e objetividade da ciência só pode ser pensada de forma distorcida, através da redução da técnica e da ciência aos seus aspectos instrumentais.

A autocompreensão cientificista das ciências, que chega à supremacia como teoria da ciência, substitui o conceito filosófico de conhecimento. Conhecimento torna-se, enquanto tal, idêntico a conhecimento científico. A ciência fica, antes de mais nada, delimitada à esfera de seus objetos e está, assim, separada de outras realizações cognitivas.(HABERMAS, 1982, p. 100).

Ou seja, tal redução do conhecimento ao conhecimento científico ocorre quando a racionalidade é reduzida à racionalidade instrumental e, em nível social, isso se manifesta através da colonização do mundo da vida pelo sistema. Aí mais uma vez a educação integrada, que educa para o pensar crítico, faz-se necessária para formar um homem capaz de tematizar discursivamente essas distorções. A questão que se coloca aqui é esta: evitar as distorções ideológicas geradas pelo positivismo, cientificismo e tecnicismo. "Se se considera que a tecnologia não é somente necessária, mas que representa uma parte do desenvolvimento natural do homem, a questão que se apresenta aos revolucionários é saber como evitar os desvios míticos da tecnologia". (FREIRE, 1980, p. 93). Um dos principais desvios a ser superado pela educação na perspectiva emancipatória é a falsa dicotomia entre formação humana e capacitação técnica.

\section{Considerações finais}

Considerando as categorias discutidas no presente artigo, podemos afirmar que a proposta de educação profissional e tecnológica em implantação nos Institutos Federais de Educação é uma tentativa de superar o histórico dual da educação brasileira que promoveu uma educação diferenciada para os trabalhadores e para as elites. Para os trabalhadores historicamente oferecia-se educação profissional, com o papel de capacitação, sem dar-lhe uma educação de qualidade, legando-o a uma tarefa marginal, distante do mundo da produção científica e cultural. O modelo em implantação nos Institutos Federais de Educação supera esse modelo dual ao priorizar o ensino técnico integrado ao ensino médio, ao promover a verticalização que possibilita a apreensão dos princípios científicos e a articulação do ensino com o desenvolvimento local e regional, 
ao promover a capacitação profissional de modo integrado com a educação cultural, política, ética e estética.

Ao buscar a formação do educando de modo integral, ou seja, possibilitando a capacitação técnico-tecnológica de modo integrado com a formação humana, o que se evidencia pelos elementos acima desenvolvidos, a proposta de educação profissional e tecnológica dos Institutos Federais de Educação constitui um novo paradigma na educação brasileira. Desse modo promove educação profissional e tecnológica a partir de uma concepção não tecnicista de técnica e ciência, abordando a educação a partir de seu lugar que é mais próprio, o mundo da vida. Mas cabe uma advertência: a proposta está em implantação, e ela não ocorre de modo isento aos interesses sistêmicos provindos do poder político e econômico. Portanto, é preciso estar atento para que o sistema não distorça a proposta reduzindo-a a uma abordagem tecnicista.

\section{REFERÊNCIAS}

BRASIL. Decreto $\mathbf{n}^{\circ} \mathbf{5 . 1 5 4}$ de 23 de julho de 2004.

BRASIL. Parecer CNE/CEB n 16 de 05 de outubro de 1999. Trata das Diretrizes Curriculares Nacionais para a Educação Profissional de Nível Técnico.

BRASIL. Lei $\mathbf{n}^{\circ} \mathbf{1 1 . 8 9 2}$ de 29 de dezembro de 2008.

FREIRE, Paulo. Ação cultural para a liberdade. $6^{\text {a }}$ ed. Rio de Janeiro: Paz e Terra, 1982.

FREIRE, Paulo. Conscientização: teoria e prática da libertação: uma introdução ao pensamento de Paulo Freire. Trad. Kátia de Mello e Silva. $3^{a}$ ed. São Paulo: Editora Moraes, 1980.

FREIRE, Paulo. Pedagogia do oprimido. 12a ed. Rio de Janeiro: Paz e Terra, 1983.

HABERMAS, Jürgen. A crise de legitimação no capitalismo tardio. Rio de Janeiro: Tempo Brasileiro, 2002a.

HABERMAS, Jürgen. Agir comunicativo e razão destrancendentalizada. Trad. Lucia Aragão. Rio de Janeiro: Tempo Brasileiro, 2002b.

HABERMAS, Jürgen. A Lógica das Ciências Sociais. 2ª ed. Petrópolis: Vozes, 2011.

HABERMAS, Jürgen. Conhecimento e interesse. Rio de Janeiro: Zahar Editores, 1982. 
HABERMAS, Jürgen. Consciência moral e agir comunicativo. Trad. Guido A. de Almeida. $2^{a}$ ed. Rio de Janeiro, 2003.

HABERMAS, Jürgen. Pensamento pós-metafísico: estudos filosóficos. Trad. Flávio Beno Siebeneichler. $2^{\mathrm{a}}$ ed. Rio de Janeiro: Tempo Brasileiro, 2002c.

HABERMAS, Jürgen. Teoria de la acción comunicativa: complementos y estúdios prévios. Madrid: Cátedra, 1989.

JURACY, Caetana. (org.). Institutos Federais Lei 11.892, de 29/12/2008. Comentários e Reflexões. Natal: IFRN, 2009.

MEC. Instituto Federal de Educação, Ciência e Tecnologia: um novo modelo em educação profissional e tecnológica. Concepção e Diretrizes. 2010. 43p.

MINAYO, Maria Cecília de Souza. Pesquisa social: teoria, método e criatividade. $28^{\mathrm{a}}$ ed. Petrópolis: Vozes, 2009.

PACHECO, Eliezer Moreira. Os Institutos Federais: uma revolução na educação profissional e tecnológica. Natal: IFRN, 2010.

RAMOS, Marise. O Ensino Médio integrado. In: MOLL, Jaqueline (Org.). Educação Profissional e Tecnológica no Brasil contemporâneo. Porto Alegre: Artmed, 2010,

STEIN, Ernildo. Mundo vivido: das vicissitudes e dos usos de um conceito da fenomenologia. Porto Alegre: EDIPUCRS, 2004.

\section{Como referenciar este artigo}

ZATTI, Vicente. Institutos federais de educação: um novo paradigma em educação profissional e tecnológica? Revista Ibero-Americana de Estudos em Educação, Araraquara/SP, v. 11, n. 3, p.1461-1480, 2016. Disponível em: <https://dx.doi.org/10.21723/riaee.v11.n3.7555>. E-ISSN: 1982-5587.

Submetido em: 20/02/2015

Aprovação final em: 28/07/2016 